\title{
Field Engineers' Scheduling at Oil Rigs: a Case Study
}

\author{
Dr. Ateekh-Ur-Rehman \\ Department of industrial Engineering \\ King Saud University, Riyadh, Saudi Arabia \\ arehman@ksu.edu.sa
}

\author{
Yusuf Usmani \\ Department of industrial Engineering \\ King Saud University, Riyadh, Saudi Arabia \\ yusmani@ksu.edu.sa
}

\begin{abstract}
Oil exploration and production operations face a number of challenges. Professional planners have to design solutions for various practical problems or issues. However, the time consumed is often very extensive because of the large number of possible solutions. Further, the matter of choosing the best solution remains. The present paper investigates a problem related to leading companies in the energy and chemical manufacturing sector of the oil and gas industry. Each company's field engineers are expensive and valuable assets. Therefore, an optimized roster is rather important. In the present paper, the objective is to design a field engineers' schedule which would be both feasible and satisfying towards the various demands of rigs, with minimum operational cost to the company. An efficient and quick optimization technique is presented to schedule the shifts of field engineers.
\end{abstract}

Keywords- Fied engineers (FE); Oil rigs; Scheduling; Uneven demand

\section{INTRODUCTION}

Scheduling is the allocation of resources over time to perform a collection of tasks. A workforce schedule that ensures appropriate service and production level is a key management function and has high practical importance. Among the terms used, predictive scheduling describes the design of a schedule in advance whereas reactive scheduling describes the adaptation of the schedule according to actual events [1]. However, due to the exponential size of the scheduling problem it is extremely difficult to find good solutions to these highly constrained and complex problems [2]. Further, providing the right people at the right time at the right cost whilst achieving a high level of employee satisfaction is another critical problem [2].

Personnel scheduling, or rostering, is the process of constructing work timetables for the staff so that $a b$ organization can satisfy the demand for its goods or services [2-3]. The origin of staff scheduling and rostering can be traced back to Edie's work on traffic delays at toll booths [4]. Since then, staff scheduling and rostering methods have been applied to transportation systems, such as airlines and railways, health care systems, emergency services, such as the police, ambulance and fire brigade, call centers and many other service organizations such as hotels, restaurants and retail stores. Therefore, extensive model and algorithm development has been carried out in the literature on crew scheduling and rostering in transportation systems, nurse scheduling in health care systems, and tour scheduling for various service systems.
A focused review on applications of both personnel and vehicle scheduling can be found in [5] where scheduling objectives, constraints, and methodologies are surveyed for each application area. Personnel scheduling has been a subject of investigation over the past 30 years with a survey in every decade. An application of such problems is presented in the following section.

The present paper is concerned with the $[\mathrm{R}, \mathrm{N}]$ days-off scheduling problem, where for a given cycle of $\mathrm{N}$ periods each field engineer is assign a work-stretch of $\mathrm{R}$ consecutive periods and break of 'N-R' consecutive periods. The focus is to address the issue related to uneven demand of field engineers for the oil rigs. The primary objective of the days-off scheduling problem is to minimize the workforce size, i.e., total number of field engineers assigned.

The paper is organized into seven sections. Section II presents literature survey on days-off scheduling approaches. Section III presents the problem in detail. The uneven demands procedures for determining the minimum workforce size and assigning workers (field engineers) to days-off patterns are presented in sections IV and V with an example. Section VI presents the case application of the model in an oil rig company. Finally, the last section concludes with the discussion.

\section{LITERATURE SURVEY}

Scheduling problems and their treatments are very diverse. The problem of designing a staffing schedule or roster (sometimes known as a tour) subject to a particular set of constraints was solved by Williams [6]. Early examples of the use of linear programming in scheduling problems were given by Baker and Magazine [7] and Bartholdi et al. [8]. The solution of a problem with some similarities was also given by Townsend [9]. An aspect of this problem was the existence of several different duties which had to be distributed fairly amongst crews. The rules governing the pattern of days on and days off were simpler. In aircrew scheduling, as described by Ryan [10], with rosters used as inputs, one aspect of the technique was allocating rosters to staff. The problem solved in his paper was the finding of a feasible schedule. Sydney [11] proposed the goal programming models for an integrated problem of crew duties assignment, for baggage services section staff. Easton and Rossin [12] used a heuristic approach to find improvements regarding the set of a feasible schedule. The problem considered by Hung [13-14] had the added complication of non-homogenous labor force (one kind of 
worker can replace another, but not vice versa) factor. Bechtold et al. [15] exemplify the approach of finding the few schedules, out of the numerous feasible schedules, which maximize certain desirable criteria. Hojati and Patil [16] considered the scheduling of heterogeneous part-time employees of service organizations. Rafael [17] described how a simple procedure, combining random and greedy strategies with heuristics, has been successfully applied in assigning guard shifts to the physicians in a department.

Workforce scheduling problems are traditionally classified into three types i.e. shift scheduling, days-off scheduling, and roster scheduling. Nanda and Browne [18] provided a thorough survey of literature on these three types. Narasimhan [19] reflected on multiple worker types, giving each worker two days off per week. Emmons and Burns [20] considered a workforce composed of $\mathrm{N}$ worker types, but assume a constant employee demand for all days of the week. The days-off scheduling model proposed by Hung [21] was based on two assumptions. The first assumption is $\mathrm{X}$ workers are required on weekdays and $\mathrm{Y}$ workers on weekends, and the second assumption was that each worker must have A out of B weekends off. Alfares [22] presented a single-shift optimum solution technique for 3-day workweeks. Similarly, Alfares [23] extended the expression for the minimum workforce size, and included it as a constraint in the linear programming. Backtracking techniques was used by Musliu et al. [24] to obtain Cyclic schedules (cyclic assignments of shifts to employees) that are optimal for weekends off, long weekends off and also in terms of the regularity of weekends off.

Some practical general scheduling applications can be found in the work of Pinedo and Chao [25], Blazewicz [26], and Pinedo [27]. The notion of skill is well known in the field of personnel scheduling [28]. Ne'ron [29] consider the resource constrained scheduling problem where resources are staff members that have one or more skill. Cai and Li [30] considered the problem of scheduling staff with mixed skills. These papers tend to emphasize problems in which the same numbers of periods are worked each cycle. Some attention is given to the important practical point of the period worked each cycle being contiguous.

\section{PROBLEM DEFINITION}

The problem on hand is concerned with one of the leading companies in the energy and chemical manufacturing sector of the oil and gas industry. The company's field engineers are typically one of its most expensive as well as one of its most valuable assets. Therefore, scheduling needs focus on how to allocate field engineers to satisfy the forecasted requirement of field engineers on duty to cover the workload. Questions that also needs answering are: what are the best roster assigning field engineers to shifts and which of them should cover a vacant shift?

The objective is to reproduce $(\mathrm{R}, \mathrm{N})$ day's on-off assigning problem, considering a ten week cycle. Here for a given cycle of 70 consecutive days, each field engineer is assigned one work stretch of 42 consecutive workdays (i.e. break of 28 consecutive days off). The main objective is to reduce the cost by optimizing the field engineers' schedule i.e. the total number of field engineers assigned. In order to reduce assignment cost, it is required to minimize the number of active days-off patterns. In the present paper, an added goal is to assign filed engineers to different rigs according to job requirement on particular oil rig. It is also evident from the literature survey, that there is the need to address issues related to mostly uneven demand of field engineers for the oil rigs. Under such circumstances field engineers are assigned to different shift types, each involving a different pattern of "on" and "off" work periods, in such a way that the number of field engineers who are "on" in each period is sufficient to meet the demand in that period. The objective is to minimize the total cost of the shift. If the cost of field engineer to a shift is the same for all shift types, then the objective is to minimize the amount by which the capacity provided by the schedule exceeds the demand. The tool used is Microsoft MS solver.

Thus, focus is given to scheduling field engineers to satisfy uneven demands of different oil rigs. The objective is to minimize the total cost of the shift. The formulation of even and uneven demand scheduling problem, the details of the solution and analysis are presented in the subsequent sections 4 and 5.

\section{FIELD ENGINEERS' SHIFTS SCHEDULING FORMULATION}

In practice, when there is a case of uneven demand of field engineers at oil rigs, the field engineers are scheduled to different shifts, involving a different pattern of "on" and "off" work periods, in such a way that the number of field engineers who are "on" in each period is sufficient to meet the demand in that period.

The present paper is concerned with the $[R, N]$ days-off scheduling problem, where for a given cycle of $\mathrm{N}$ periods each field engineer is assign a work-stretch of $\mathrm{R}$ consecutive periods and break of ' $\mathrm{N}-\mathrm{R}$ ' consecutive periods

Let's consider a $[\mathrm{R}, \mathrm{N}]$ days-off scheduling problem, where for a given cycle of $\mathrm{N}$ periods each field engineer is assign a work-stretch of R consecutive periods. There are ' $\mathrm{N}$ ' schedule patterns. Each field engineer is assigned to exactly one shift pattern, so that he/she will be on 'N-R' consecutive periods off. The scheduling for ' $\mathrm{m}$ ' periods,

Where,

$b_{i}=$ Number of field engineer required on oil rigs during period i.

$X_{j}=$ Number of field engineer assigned to shift pattern $\mathrm{j}$.

$E_{i}=$ Number of field engineer called on emergency in period i.

$\mathrm{C}_{\mathrm{j}}=$ Cost of a field engineer on normal duty assigned to shift pattern $\mathrm{j}$.

$\mathrm{C}_{\mathrm{ei}}=$ Cost of a field engineer called on emergency in period i.

The problem can be formulated as presented hereunder. 
Let constraint matrix $A=\left[a_{i j}\right]$, where row ' $i$ ' corresponds to period and column ' $\mathrm{j}$ ' corresponds to shift pattern. So that,

$a_{i j}=1$, if period $\mathrm{i}$ is an 'on' period in shift pattern $\mathrm{j}$.

$=0$, otherwise.

Min $Z=\sum_{j=1}^{N} C_{j} X_{j}+\sum_{i=1}^{m} C_{e i} E_{i}$

Subjected to

$$
\begin{array}{ll}
\sum_{j=1}^{N} a_{i j} X_{j}+E_{i} \geq b_{i} & (\text { for } \quad i=1,2, \ldots \ldots . m) \\
\sum_{j=1}^{N} a_{i j} X_{j}+E_{i} \leq \sum_{j=1}^{N} X_{j} & (\text { for } \quad i=1,2, \ldots \ldots . m)
\end{array}
$$

$\mathrm{X}_{\mathrm{j}}, \mathrm{E}_{\mathrm{i}} \geq 0$ and integer

$$
\text { (for } \mathrm{i}=1,2 \ldots \ldots . \mathrm{m} \text {. and } \mathrm{j}=1,2, \ldots . \mathrm{N} \text {. ) }
$$

The objective function is to minimize the field engineer scheduling cost including the cost of calling the field engineers on emergency if required. There is the constraint that one should have enough field engineers to operate the rigs in each period. So, the first constraint set ensures that sufficient number of filed engineers is provided to meet or exceed the minimum demand of field engineers at oil rigs for the period. There is also another constraint that, a field engineer should be called on emergency duty only when he is on an off period. The second constraint limits the availability of field engineers on emergency basis in every period. The third constraint set place non-negativity and integer restriction on the decision variables. The application of the above formulation is illustrated with an example hereunder.

\section{A. Computational illustration}

Let's consider the situation of a cycle of 10 weeks where field engineers are schedules on 6 weeks consecutive on shift and 4 weeks consecutive off shift. MS Solver is used to find a schedule that uses the fewest number of field engineers and meets all weekly demands of field engineers at oil rigs. There is a need of certain number of field engineers to meet the oil rigs' demand. A cycle consists of 10 periods. In other words there are 10 schedule patterns.

For computational illustration as presented in Table I, there are ten different schedule patterns (S1 to S10) each pattern have consecutive 4 weeks off (represented in column B). There are ten weeks (W1 to W10). As presented in Table I, Cell $(\mathrm{C} 2: \mathrm{C} 11)$ in column $\mathrm{C}$ which have been set equal to zero at the start. MS Excel refers to these cells as changing cells in MS Solver. These changing cells are the number of field engineers required to meet demand. As the objective is to minimize cost (value in cell $\mathrm{C} 15$ ), it is calculated by multiplying total demand required during 10 week periods and pay per field engineer per day. MS Solver refers to this as the "Target Cell" and it corresponds to the objective function defined. As presented in Table I, cells D12 to M12 the allocation total field engineers for a period is calculated by multiplying and adding the number of workmen in Cells C2:C11 with Cells D2:D11 for result of Cell D12 $(\mathrm{D} 12=\mathrm{C} 1 * \mathrm{D} 1+\ldots . .+\mathrm{C} 11 * \mathrm{D} 11)$. The results of cells E12 through M12 will be calculated in same manners. The oil rig demands in these periods are entered in cells D13 to M13. Using MS solver, the objective to minimize the cost for ten periods by optimizing the number of field engineers required to meet demand is calculated and presented in cell C15 of Table I. MS solver acknowledges that a solution was found that appears

\begin{tabular}{|c|c|c|c|c|c|c|c|c|c|c|c|c|c|}
\hline $\begin{array}{c}\text { Columns } \rightarrow \\
\text { Rows } \downarrow \\
\end{array}$ & A & B & $\mathrm{C}$ & $\mathrm{D}$ & $\mathrm{E}$ & $\mathrm{F}$ & $\mathrm{G}$ & $\mathrm{H}$ & I & $\mathrm{J}$ & $\mathrm{K}$ & $\mathrm{L}$ & M \\
\hline \multirow[b]{2}{*}{1} & \multirow{2}{*}{\multicolumn{2}{|c|}{ Schedules }} & \multirow[b]{2}{*}{ FE } & \multicolumn{10}{|c|}{ Week } \\
\hline & & & & 1 & 2 & 3 & 4 & 5 & 6 & 7 & 8 & 9 & 10 \\
\hline 2 & S1 & W1,W2,W3,W4 & 2 & 0 & 0 & 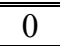 & 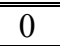 & 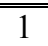 & 1 & 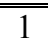 & $\overline{11}$ & 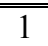 & 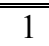 \\
\hline 3 & $\mathrm{~S} 2$ & W2,W3,W4,W5 & 3 & 1 & 0 & 0 & 0 & 0 & 1 & 1 & 1 & 1 & 1 \\
\hline 4 & S3 & W3,W4,W5,W6 & 2 & 1 & 1 & 0 & 0 & 0 & 0 & 1 & 1 & 1 & 1 \\
\hline 5 & S4 & W4,W5,W6,W7 & 1 & 1 & 1 & 1 & 0 & 0 & 0 & 0 & 1 & 1 & 1 \\
\hline 6 & S5 & W5,W6,W7,W8 & 3 & 1 & 1 & 1 & 1 & 0 & 0 & 0 & 0 & 1 & 1 \\
\hline 7 & S6 & W6,W7,W8,W9 & 1 & 1 & 1 & 1 & 1 & 1 & 0 & 0 & 0 & 0 & 1 \\
\hline 8 & S7 & $\mathrm{W} 7, \mathrm{~W} 8, \mathrm{~W} 9, \mathrm{~W} 10$ & 2 & 1 & 1 & 1 & 1 & 1 & 1 & 0 & 0 & 0 & 0 \\
\hline 9 & S8 & $\mathrm{W} 1, \mathrm{~W} 8, \mathrm{~W} 9, \mathrm{~W} 10$ & 1 & 0 & 1 & 1 & 1 & 1 & 1 & 1 & 0 & 0 & 0 \\
\hline 10 & S9 & $\mathrm{W} 1, \mathrm{~W} 2, \mathrm{~W} 9, \mathrm{~W} 10$ & 6 & 0 & 0 & 1 & 1 & 1 & 1 & 1 & 1 & 0 & 0 \\
\hline 11 & $\mathrm{~S} 10$ & $\mathrm{~W} 1, \mathrm{~W} 2, \mathrm{~W} 3, \mathrm{~W} 10$ & 0 & 0 & 0 & 0 & 1 & 1 & 1 & 1 & 1 & 1 & 0 \\
\hline 12 & \multicolumn{2}{|c|}{ Total FE Scheduled } & 21 & 12 & 10 & 14 & 13 & 12 & 14 & 14 & 14 & 11 & 12 \\
\hline 13 & \multicolumn{2}{|c|}{ Weekly Total Demand of FE } & & 12 & 10 & 14 & 12 & 12 & 14 & 14 & 14 & 10 & 12 \\
\hline 14 & \multicolumn{2}{|r|}{ Cost/FE/Week } & $\$ 3500$ & & & & & & & & & & \\
\hline 15 & \multicolumn{2}{|r|}{ Cost for 10 Period } & $\$ 441000$ & & & & & & & & & & \\
\hline
\end{tabular}
to be optimal and the obtained results are presented in Table I. From the results one can see that the number of employees in different schedule pattern is allocated.

TABLE I. SCHEDULING OF FIELD ENGINEER (FE) FOR DIFFERENT SHIFT PATTERN USING MS SOLVER 
The solution presented will not satisfy the oil company requirements to plan work shifts to approximately match the requests as per service. There is also the issue of how will the solution affect the utilization of personnel time, group morale and time required to perform customer service. The subsequent section presents field engineers' scheduling using heuristic model.

\section{A HEURISTIC APPROACH}

Any oil company wants to plan work shifts to approximately match the requests for the service. It is also concerned about the schedules affecting the utilization of personnel time, group morale and time required to perform the required service. In the present section, the same scenario as presented in section 4 , which relates to 6 weeks on and 4 week off shift schedules to weekly numbers of field engineers available, is considered. A heuristic model is used to find a schedule that uses the smaller number of field engineers and meets all oil rigs' demands. The requirements of the modelcan be formulated in the following question: what is the number of required field engineers and what ways could be used to reduce the amount of slack in the work shift schedules? Thus, the model uses a "work shift heuristic procedure" to develop shift schedules for field engineers.

The heuristic rule is stated as: choose two consecutive periods with least total number of field engineers required. In the case of ties, arbitrarily select a pair and continue. This heuristic was originally developed by Baker and Magazine [7]. For the problem on hand as presented in section 3, the company needs a field engineers' schedule that provides six weeks on duty and four weeks off which minimizes the amount of total slack capacity. For simplicity let's consider one cycle of 10 weeks and each week stands for seven working days. The number of workmen required in each week is the same as in cells D13 to M13 of Table 1, the same is presented in Table II. The subsequent subsection presents the steps followed to illustrate the above mentioned heuristic approach using an example.

\section{A. Steps}

Step 1 Find all the pairs of consecutive days that exclude the maximum daily requirements. Select the unique pair that has the lowest total requirements for the 4 periods (Weeks). Periods 3 and 7 contains the maximum requirements (7), and periods 1, 2, 9 and 10 have the lowest total requirements. Therefore, field engineer 1 is scheduled to work for period 3 to period 8 without a break, as presented in Table II.

Step 2 If a tie occurs, choose one of the tied pairs or ask the field engineer to make a choice and continue.

TABLE II. FIELD ENGINEERS (FE) SCHEDULE USING HEURISTIC APPROACH

\begin{tabular}{|c|c|c|c|c|c|c|c|c|c|c|c|}
\hline & & & & & & & & & & & \\
\hline & 1 & 2 & 3 & 4 & 5 & 6 & 7 & 8 & 9 & 10 & \\
\hline Total Demand of field engineers & 5 & 5 & 7 & 6 & 5 & 6 & 7 & 6 & 5 & 6 & \\
\hline Schedule of field engineer 1 & off & off & on & on & on & on & on & on & off & off & \\
\hline Net demand after $1^{\text {st }}$ iteration & 5 & 5 & 6 & 5 & 4 & 5 & 6 & 5 & 5 & 6 & \\
\hline Schedule of field engineer 2 & on & on & off & off & off & off & on & on & on & on & \\
\hline Net demand after $2^{\text {nd }}$ iteration & 4 & 4 & 6 & 5 & 4 & 5 & 5 & 4 & 4 & 5 & \\
\hline Schedule of field engineer 3 & off & off & on & on & on & on & on & on & off & off & \\
\hline Net demand after $3^{\text {rd }}$ iteration & 4 & 3 & 5 & 4 & 3 & 4 & 4 & 3 & 4 & 5 & \\
\hline Schedule of field engineer 4 & on & on & on & on & off & off & off & off & on & on & \\
\hline Net demand after $4^{\text {th }}$ iteration & 3 & 2 & 4 & 3 & 3 & 4 & 4 & 3 & 3 & 4 & \\
\hline Schedule of field engineer 5 & off & off & off & off & on & on & on & on & on & on & \\
\hline Net demand after $5^{\text {th }}$ iteration & 3 & 2 & 4 & 3 & 2 & 3 & 3 & 2 & 2 & 3 & \\
\hline Schedule of field engineer 6 & off & off & on & on & on & on & on & on & off & off & \\
\hline Net demand after $6^{\text {th }}$ iteration & 3 & 2 & 3 & 2 & 1 & 2 & 2 & 1 & 2 & 3 & \\
\hline Schedule of field engineer 7 & on & on & on & on & off & off & off & off & on & on & \\
\hline Net demand after $7^{\text {th }}$ iteration & 2 & 1 & 2 & 1 & 1 & 2 & 2 & 1 & 1 & 2 & \\
\hline Schedule of field engineer 8 & on & off & off & off & off & on & on & on & on & on & \\
\hline Net demand after $8^{\text {th }}$ iteration & 1 & 1 & 2 & 1 & 1 & 1 & 1 & 0 & 0 & 1 & \\
\hline Schedule of field engineer 9 & on & on & on & on & on & off & off & off & off & on & \\
\hline Net demand after $9^{\text {th }}$ iteration & 0 & 0 & 1 & 0 & 0 & 1 & 1 & 0 & 0 & 0 & \\
\hline Schedule of field engineer 10 & off & on & on & on & on & on & on & off & off & off & Total \\
\hline Total FE scheduled, C & 5 & 5 & 7 & 7 & 6 & 6 & 7 & 6 & 5 & 6 & 60 \\
\hline Total demand of FE, D & 5 & 5 & 7 & 6 & 5 & 6 & 7 & 6 & 5 & 6 & 58 \\
\hline Slack, C-D & 0 & 0 & 0 & 1 & 1 & 0 & 0 & 0 & 0 & 0 & 2 \\
\hline
\end{tabular}


Step 3 Subtract the requirements satisfied by the field engineer 1 from the net requirements for each period (week) the field engineer is to work and repeat step one. In continuation with above step it is observed that periods $1,2,9$ and 10 has the lowest total requirements. Therefore, field engineer 2 is scheduled to work for period 3 to period 8 as presented in Table II.

Step 4 Repeat steps 1 through 3 until all the requirements have been satisfied. After field engineers 1, 2, and 3 have reduced the requirements, the period with the lowest requirements changes and field engineer 4 will be scheduled for periods $6,7,8,9,10$ and 1 .

The above steps 1 to 3 are repeated until the schedule for individual field engineers can be planned such that all demands are met. The details are presented in Table II. The application of the above methods and the discussion is presented in the following section.

\section{FIELD ENGINEERS' SCHEDULING IN AN OIL COMPANY: A CASE STUDY}

The above presented model of uneven demand has been applied successfully at an oil company. The ultimate objective was to optimize the number of field engineers required to meet the demand and minimizing the total cost

The relevant data was collected for 6 months, from January 2009 to June 2009. It is observed that the numbers of field engineers available for oil rigs are twenty. The number of jobs "running" during this period was four to seven. Two field engineers were required on each job. The schedule for each field engineer is considered as 42 days on shift / 28 days off shift (continuous 6 weeks on and 4 weeks off). The details of the data available and the scheduling cost without using any optimizing techniques are as presented in Table II. It's observed that without using an optimization tool the field engineers are allotted throughout the shifts. Because of this approach during a period of uneven demand the company had to call field engineers (particularly those that were on an off shift) back on duty on emergency call with higher bonuses. It was observed that field engineers were called on emergency duties twenty times during periods of high demand, whereas there were some incidences were demand was too low and the company was holding the field engineers on rigs without work, which is an idle cost incurred by the company. As presented in Table II the total cost incurred by the company without following an optimization technique for field engineer scheduling is found to be $\$ 1,169,000$.

After application of the proposed models it is observed that there is no need to call field engineers on emergency duty. The brief results obtained after the application of the proposed model are as presented in Table IV. As presented in Table IV, the total cost incurred by the company with following optimization techniques for field engineer scheduling is found to be $\$ 945,000$.
TABLE III. SCHEDULING RESULT AND TOTAL COST BEFORE APPLYING SCHEDULING OPTIMIZATION TECHNIQUES

\begin{tabular}{|c|c|c|c|c|c|c|c|c|}
\hline 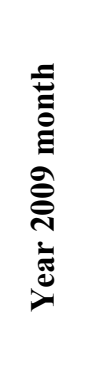 & $\begin{array}{l}\dot{0} \\
\dot{z} \\
\dot{d} \\
\dot{8}\end{array}$ & $\begin{array}{l}\frac{0}{0} \\
\stackrel{0}{0} \\
\dot{0} \\
\dot{z}\end{array}$ & 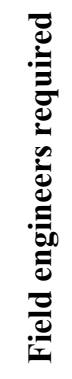 & 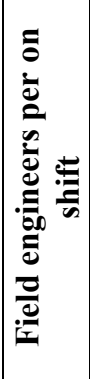 & 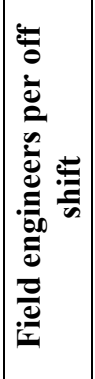 & 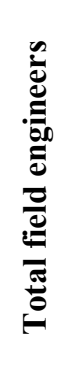 & 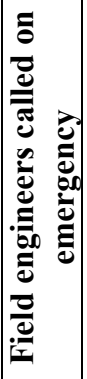 & 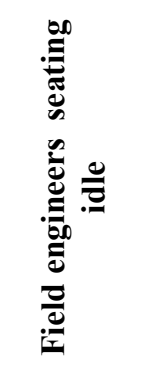 \\
\hline \multirow{22}{*}{ 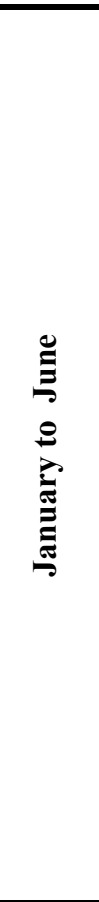 } & 1 & 4 & 8 & 8 & 12 & 20 & & \\
\hline & 2 & 6 & 12 & 12 & 8 & 20 & & \\
\hline & 3 & 6 & 12 & 11 & 9 & 20 & 1 & \\
\hline & 4 & 7 & 14 & 12 & 8 & 20 & 2 & \\
\hline & 5 & 5 & 10 & 12 & 8 & 20 & & 2 \\
\hline & 6 & 7 & 14 & 12 & 7 & 19 & 2 & \\
\hline & 7 & 5 & 10 & 9 & 10 & 19 & 1 & \\
\hline & 8 & 4 & 8 & 10 & 10 & 20 & & 2 \\
\hline & 9 & 6 & 12 & 12 & 8 & 20 & & \\
\hline & 10 & 6 & 12 & 10 & 10 & 20 & 2 & \\
\hline & 11 & 7 & 14 & 12 & 8 & 20 & 2 & \\
\hline & 12 & 6 & 12 & 11 & 9 & 20 & 1 & \\
\hline & 13 & 6 & 12 & 10 & 10 & 20 & 2 & \\
\hline & 14 & 5 & 10 & 10 & 10 & 20 & & \\
\hline & 15 & 7 & 14 & 12 & 8 & 20 & 2 & \\
\hline & 16 & 6 & 12 & 12 & 8 & 20 & & \\
\hline & 17 & 6 & 12 & 11 & 8 & 19 & 1 & \\
\hline & 18 & 7 & 14 & 12 & 8 & 20 & 2 & \\
\hline & 19 & 7 & 14 & 14 & 6 & 20 & & \\
\hline & 20 & 7 & 14 & 12 & 8 & 20 & 2 & \\
\hline & 21 & 5 & 10 & 12 & 8 & 20 & & 2 \\
\hline & 22 & 6 & 12 & 12 & 8 & 20 & & \\
\hline Total & 22 & 131 & 262 & 248 & 189 & 437 & 20 & 6 \\
\hline \multicolumn{8}{|c|}{ A. Number of days per shift } & 7 \\
\hline \multicolumn{8}{|c|}{ B. Cost per field engineer per day (if on duty) } & $\$ 500$ \\
\hline \multicolumn{8}{|c|}{$\begin{array}{l}\text { C. Extra cost per day if field engineer called on } \\
\text { emergency duty }\end{array}$} & $\$ 2000$ \\
\hline \multicolumn{8}{|c|}{$\begin{array}{l}\text { D. Total number of field engineers on normal } \\
\text { shift }\end{array}$} & 248 \\
\hline \multicolumn{8}{|c|}{$\begin{array}{l}\text { E. Total number of field engineers called on } \\
\text { emergency duty }\end{array}$} & 20 \\
\hline \multicolumn{8}{|c|}{$\begin{array}{l}\text { F. Total number of field engineers seating idle on } \\
\text { normal duty }\end{array}$} & 6 \\
\hline \multicolumn{8}{|c|}{$\begin{array}{l}\text { G. Total cost of field engineers on normal duties } \\
=(\mathrm{A} \times \mathrm{B} \times \mathrm{D})\end{array}$} & $\$ 868000$ \\
\hline \multicolumn{8}{|c|}{$\begin{array}{l}\text { H. Total extra cost if field engineers called on } \\
\text { emergency duty }=(\mathrm{A} \times \mathrm{C} \times \mathrm{E})\end{array}$} & $\$ 280000$ \\
\hline \multicolumn{8}{|c|}{ I. Total cost for idle field engineers $=(\mathrm{A} \times \mathrm{B} \times \mathrm{F})$} & $\$ 21000$ \\
\hline \multicolumn{8}{|c|}{ J. Total cost for period $=(\mathrm{G}+\mathrm{H}+\mathrm{I})$} & $\$ 1169000$ \\
\hline
\end{tabular}


TABLE IV. SCHEDULING RESULT AND TOTAL COST AFTER APPLYING SCHEDULING OPTIMIZATION TECHNIQUES

\begin{tabular}{|c|c|c|c|c|c|c|c|c|}
\hline 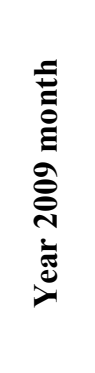 & $\begin{array}{l}\dot{0} \\
\dot{z} \\
\dot{d} \\
\dot{8}\end{array}$ & $\begin{array}{l}\frac{0}{0} \\
\stackrel{0}{0} \\
\dot{0} \\
\dot{z}\end{array}$ & 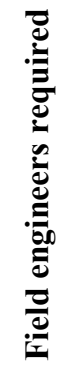 & 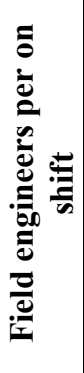 & 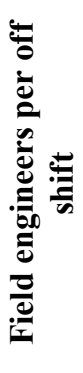 & 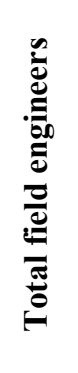 & 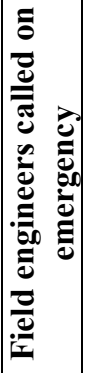 & 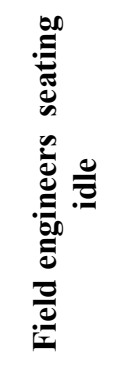 \\
\hline \multirow{22}{*}{ 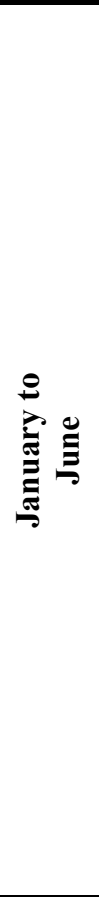 } & 1 & 4 & 8 & 8 & 12 & 20 & & \\
\hline & 2 & 6 & 12 & 12 & 8 & 20 & & \\
\hline & 3 & 6 & 12 & 12 & 8 & 20 & & \\
\hline & 4 & 7 & 14 & 14 & 6 & 20 & & \\
\hline & 5 & 5 & 10 & 10 & 10 & 20 & & \\
\hline & 6 & 7 & 14 & 14 & 5 & 19 & & \\
\hline & 7 & 5 & 10 & 11 & 8 & 19 & & 1 \\
\hline & 8 & 4 & 8 & 8 & 12 & 20 & & \\
\hline & 9 & 6 & 12 & 12 & 8 & 20 & & \\
\hline & 10 & 6 & 12 & 12 & 8 & 20 & & \\
\hline & 11 & 7 & 14 & 14 & 6 & 20 & & \\
\hline & 12 & 6 & 12 & 12 & 8 & 20 & & \\
\hline & 13 & 6 & 12 & 12 & 8 & 20 & & \\
\hline & 14 & 5 & 10 & 11 & 9 & 20 & & 1 \\
\hline & 15 & 7 & 14 & 14 & 6 & 20 & & \\
\hline & 16 & 6 & 12 & 13 & 7 & 20 & & 1 \\
\hline & 17 & 6 & 12 & 12 & 7 & 19 & & \\
\hline & 18 & 7 & 14 & 14 & 6 & 20 & & \\
\hline & 19 & 7 & 14 & 14 & 6 & 20 & & \\
\hline & 20 & 7 & 14 & 14 & 6 & 20 & & \\
\hline & 21 & 5 & 10 & 11 & 9 & 20 & & 1 \\
\hline & 22 & 6 & 12 & 12 & 8 & 20 & & \\
\hline Total & 22 & 131 & 262 & 266 & 171 & 4337 & 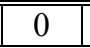 & 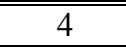 \\
\hline \multicolumn{8}{|c|}{ A. Number of days per shift } & 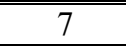 \\
\hline \multicolumn{8}{|c|}{ B. Cost per field engineer per day (if on duty) } & $\$ 500$ \\
\hline \multicolumn{8}{|c|}{$\begin{array}{l}\text { C. Extra cost per day if field engineer called on } \\
\text { emergency duty }\end{array}$} & $\$ 2000$ \\
\hline \multicolumn{8}{|c|}{$\begin{array}{l}\text { D. Total number of field engineers on normal } \\
\text { shift }\end{array}$} & 266 \\
\hline \multicolumn{8}{|c|}{$\begin{array}{l}\text { E. Total number of field engineers called on } \\
\text { emergency duty }\end{array}$} & 0 \\
\hline \multicolumn{8}{|c|}{$\begin{array}{l}\text { F. Total number of field engineers seating idle on } \\
\text { normal duty }\end{array}$} & 4 \\
\hline \multicolumn{8}{|c|}{$\begin{array}{l}\text { G. Total cost of field engineers on normal duties } \\
=(A \times B \times D)\end{array}$} & $\$ 931000$ \\
\hline \multicolumn{8}{|c|}{$\begin{array}{l}\text { H. Total extra cost if field engineers called on } \\
\text { emergency duty }=(A \times C \times E)\end{array}$} & $\$ 00000$ \\
\hline \multicolumn{8}{|c|}{ I. Total cost for idle field engineers $=(\mathrm{A} \times \mathrm{B} \times \mathrm{F})$} & $\$ 14000$ \\
\hline \multicolumn{8}{|c|}{ J. Total cost for period $=(\mathrm{G}+\mathrm{H}+\mathrm{I})$} & $\$ 945000$ \\
\hline
\end{tabular}

\section{CONCLUSION AND DISCUSSION}

The present paper demonstrated the $[\mathrm{R}, \mathrm{N}]$ days-off scheduling problem. The focus is to address the issue related to uneven demand of field engineers for the oil rigs.

Here the primary objective of the days-off scheduling problem was to minimize the workforce size, i.e., total number of field engineers assigned, in order to reduce the transportation costs. However, a model that does not consider demands, which may get cancel or amended unpredictably at the last moment due to unavoidable reason, faces limitations. As a result, the schedule of field engineers can be subjected to last minute changes. However, it is possible to minimize the number of field engineers required on site, which results in subsequent cost savings. On occasion, when field engineers are called (on emergency) for work before his or her days off the extra cost of transportation and payroll occurs. All these can be optimized by using the approach suggested in this paper. The company can benefit not only in terms of saving but also in terms of providing to its field engineers life quality leading to increased retention. Generally, company's planners may modify provisional work assignments and review business objectives at any time, since the working environment itself (weather, traffic conditions) is unpredictable. Owing to limitations of the study, the present paper includes limited variables regarding field engineers' scheduling. As a future goal, the above model can include added variables, such as stochastic demand of field engineers at oil rigs and working conditions.

\section{ACKNOWLEDGMENT}

Authors would like thank Mr. Vinod Agrahari of the client organization for introducing them to this problem and his help specially in obtaining data.

\section{REFERENCES}

[1] S. F. Smith, "Knowledge-based production management: approaches, results and prospects", Production Planning \& Control, Vol. 3, No. 4, pp. 350-380, 1992

[2] A. T. Ernst, H. Jiang, M. Krishnamoorthy, D. Sier, "Staff scheduling and rostering: a review of applications, methods and models", European Journal of Operational Research, Vol. 153, pp. 3-27, 2004

[3] J. Berg van Den, D. Panton, "Personnel shift assignment: existence conditions and network models", Networks, Vol. 24, pp. 385-394, 1994

[4] L. Edie, "Traffic delays at toll booths", Journal of the Operations Research Society of America, Vol. 2, No. 2, pp. 107-138, 1954

[5] S. Aggarwal, "A focused review of scheduling in services", European Journal of Operational Research, Vol. 9, No. 2, pp. 114-121, 1982

[6] H. P. Williams, Model building in mathematical programming, John Wiley and Sons, 1993

[7] K. R. Baker, M. Magazine, "Workforce scheduling with cyclic demands and day-off constraints", Management Science, Vol. 24, No.2, pp. 161170,1977

[8] J. J. Barthoidi, J. B. Orlin, H. D. Ratliff, "Cyclic scheduling via integer programs with circular ones", Operations Research, Vol. 28, No. 5, pp. 1074-1085, 1980

[9] W. Townsend, "An approach to bus-crew roster design in London regional transport", Journal of the Operational Research Society, Vol. 39, No. 6, pp. 543-550, 1988

[10] D. M. Ryan, "The solution of massive generalized set partitioning problems in aircrew rostering", Journal of the Operational Research Society, Vol. 43, No. 5, pp. 459-467, 1992 
[11] S. C. K. Chu, "Generating, scheduling and rostering of shift crewduties: Application at the Hong Kong International Airport", European Journal of Operational Research, Vol. 177, No. 3, pp. 1764-1778, 2007

[12] F. F. Easton, D. F. Rossin, "Equivalent alternate solutions for the tour scheduling problem", Decision Sciences, Vol. 22, pp. 985-1007, 1991

[13] R. Hung, "Single-shift off-day scheduling of a hierarchical workforce with variable demands", European Journal of Operational Research, Vol. 78, No. 1, pp. 49-57, 1994

[14] R. Hung, "Multiple-shift workforee scheduling under the 3-4 workweek with different weekday and weekend labour requirements", Management Science, Vol. 40, No. 2, pp. 280-284, 1994

[15] S. E. Bechtold, M. J. Brusco, "Working set generation methods for labour tour scheduling", European Journal of Operational Research, Vol. 74, No. 3, pp. 540-551, 1994

[16] M. Hojati, A. S. Patil , "An integer linear programming - based heuristic for scheduling heterogeneous, part-time service employees", European Journal of Operational Research, Vol. 209, No. 1, pp. 37-50, 2011

[17] R. C. Carrasco, "Long-term staff scheduling with regular temporal distribution", Computer Methods and Programs in Biomedicine, Vol. 100, No. 2, pp. 191-199, 2010

[18] R. Nanda, J. Browne, Introduction to employee scheduling, Van Nostrand Reinhold, New York, 1992

[19] N. Narasimhan, "An algorithm for single shift scheduling of hierarchical workforce”, European Journal of Operational Research, Vol. 96, pp. 113-121, 1996

[20] H. Emmons, R. N. Burns, "Off-day scheduling with hierarchical worker categories”, Operations Research, Vol. 39, No. 3, pp. 484-495, 1991
[21] R. Hung, "Single-shift workforce scheduling model under a compressed workweek", OMEGA, Vol. 19, pp. 494-497, 1991

[22] H. K. Alfares, "Optimum compressed workweek scheduling", Proceedings of the 22nd International Conference on Computers \& Industrial Engineering, Cairo, pp. 13-16, 1997

[23] H. K. Alfares, "An efficient two-phase algorithm for cyclic days-off scheduling”, Computers \& Operations Research, Vol. 25, No. 11, pp. 913-923, 1998

[24] N. Musliu, J. Gaertner, W. Slany, "Efficient generation of rotating workforce schedules", Discrete Applied Mathematics, Vol. 118, No. 12, pp. 85-98, 2002

[25] M. Pinedo, X. Chao, Operations scheduling with applications in manufacturing and services, McGraw-Hill, Computer Science Series, 1999

[26] J. Blazewicz, K. Ecker, E. Pesch, G. Schmidt, J. Weglarz, Scheduling Computer and manufacturing processes, Springer, New York, 2001

[27] M. Pinedo, Scheduling. Theory, algorithms and systems, Prentice Hall, 2002

[28] "Staff scheduling and rostering: Theory and applications. Part I", Annals of Operations Research, Speciall Issue, Vol. 127, No. 1-4, 2004

[29] E. Ne'ron, "Lower bounds for the multi-skill project scheduling problem", 8th International Workshop on Project Management and Scheduling, Valencia, Spain, 2002.

[30] X. Cai, K. N. Li, "A genetic algorithm for scheduling staff of mixed skills under multi-criteria", European Journal of Operational Research, Vol. 125, No. 2, pp. 359-369, 2000 